\title{
Lactobacillus brantae sp. nov., isolated from faeces of Canada geese (Branta canadensis)
}

\author{
Correspondence \\ Dmitriy V. Volokhov \\ dmitriy.volokhov@fda.hhs.gov
}

\author{
Dmitriy V. Volokhov, ${ }^{1}$ Megan Amselle, ${ }^{2}$ Brian J. Beck, ${ }^{2}$ David L. Popham, ${ }^{3}$ \\ Paul Whittaker, ${ }^{4}$ Hua Wang, ${ }^{4}$ Elizabeth Kerrigan ${ }^{2}$ and Vladimir \\ E. Chizhikov ${ }^{1}$ \\ ${ }^{1}$ Center for Biologics Evaluation and Research, US Food and Drug Administration, \\ 1401 Rockville Pike, HFM-470, Rockville, MD 20852, USA
${ }^{2}$ American Type Culture Collection (ATCC), 10801 University Boulevard, Manassas, VA 20110, USA
${ }^{3}$ Department of Biological Sciences, Virginia Tech, Life Sciences I - MC0910, Blacksburg, VA 24061, USA
${ }^{4}$ Center for Food Safety and Applied Nutrition, US Food and Drug Administration, 5100 Paint Branch Parkway, College Park, MD 20740, USA

At the time of writing, the genus Lactobacillus contained more than 150 species and subspecies (http://www. bacterio.cict.fr/l/lactobacillus.html) (Claesson et al., 2007,

Abbreviations: FAME, fatty acid methyl ester; ITS, intergenic transcribed spacer region; LAB, lactic acid bacteria.

The GenBank/EMBL/DDBJ accession numbers for the 16S-ITS-23S $r p o B$ and rpoC sequences of Lactobacillus saniviri DSM $24301^{\top}$ are JN644756, JN644760, and JN644761, respectively. The GenBank/ EMBL/DDBJ accession numbers for the 16S-ITS-23S, rpoB, rpoA, rpoC, and pheS sequences of strain SL1108 ${ }^{\top}$ are HQ022861, HQ022858, H0917698, JN644762 and JN644763, respectively. The GenBank/ EMBL/DDBJ accession number for an unknown DNA sequence of strain SL1108 ${ }^{\top}$ amplified with gyrB primers is JF313457.

Four supplementary figures and three supplementary tables are available with the online version of this paper.
2008; Felis \& Dellaglio, 2007). Species of the genus Lactobacillus have been isolated from a wide range of hosts and environmental matter (Claesson et al., 2008; London, 1976), and many of them are known to provide a beneficial effect in their natural hosts (Ohashi \& Ushida, 2009; Patterson \& Burkholder, 2003). During a study aimed at the isolation of lactobacilli from different environmental samples in March-August 2010, we isolated several species of lactic acid bacteria (LAB), including Lactobacillus sakei, Lactobacillus reuteri, Lactobacillus plantarum, Lactobacillus fermentum and Lactobacillus lactis, from the faeces of apparently healthy wild Canada geese (Branta canadensis). LAB microflora of geese and other Anseriformes remains to be elucidated with only a few publications describing $\mathrm{LAB}$ diversity in these avian hosts (Angelakis \& Raoult, 2010; 
Damaré et al., 1979; Ehrmann et al., 2002; Kovalenko et al., 1989; Kurzak et al., 1998). Isolation of species of the genus Lactobacillus, including Lactobacillus coryniformis, L. plantarum and Lactobacillus acidophilus, has been reported from geese (Damaré et al., 1979; Kovalenko et al., 1989), but other LAB including Enterococcus faecium and Enterococcus faecalis were found to be the most prevalent species in the digestive tract of geese and ducks (Kovalenko et al., 1989; Kurzak et al., 1998). Among species of the genus Lactobacillus, the predominant isolate from geese has been L. plantarum, and it was suggested that this observation can be explained by the herbivore diet of geese (Kovalenko et al., 1989), and by the fact that $L$. plantarum are a frequent associate of epiphytic microflora of terrestrial plants (Endo et al., 2010; Mundt \& Hammer, 1968).

In this study, we describe a novel species of the genus Lactobacillus, which was isolated from the faeces of Canada geese and demonstrated low $16 \mathrm{~S}$ rRNA gene sequence similarity to all previously described $\mathrm{LAB}$, and had distinctive biochemical features. Ten faecal specimens were collected from Canada geese in Great Falls Park and Assateague State Park, Maryland, USA. Faecal specimens (1 g per bird) were diluted $1: 10(\mathrm{w} / \mathrm{v})$ in sterile PBS and serially diluted in PBS. Aliquots from $10^{-1}$ to $10^{-5}$ dilutions were either inoculated 1:20 (v/v) into Rogosa SL broth (Difco; BD) or $0.5 \mathrm{ml}$ of each dilution were plated on Rogosa SL agar. Broth and plates were incubated at $36 \pm 1{ }^{\circ} \mathrm{C}$ under aerobic conditions with $5 \% \mathrm{CO}_{2}$. Bacterial growth in broth and on plates was observed after 2-3 days. The broth samples where bacterial growth was visibly detected were streaked on Rogosa SL agar and incubated under the same conditions. Individual colonies from Rogosa SL agar were subcultivated on MRS agar (Difco; BD) under both aerobic and anaerobic conditions. Following triple subculturing from single colonies, the isolates were maintained in MRS broth (Difco; BD). The almost complete 16S rRNA gene sequence (Pérez Pulido et al., 2005) of the randomly selected colonies suggested that most isolates were represented by the abovementioned known LAB, which were later also confirmed by partial sequencing of their housekeeping genes $(r p o B, r p o A$ and $g y r B)$. However three isolates had a $16 \mathrm{~S}$ rRNA gene sequence different from the 16S rRNA gene sequences of all LAB available in the GenBank database. The three isolates were designated SL1108 ${ }^{\mathrm{T}}$, SL1170 and SL60106, and were isolated in June, July and August 2010, respectively. Strain SL $1108^{\mathrm{T}}$ was selected as the type strain for the novel species because it was isolated first.

The three isolates grew readily on MRS agar and on Trypticase Soy Agar (TSA) with $5 \%$ sheep blood. When incubated at $36 \pm 1{ }^{\circ} \mathrm{C}$, good growth appeared in $48 \mathrm{~h}$ under both aerobic and anaerobic conditions. An aerobic atmosphere of $5 \% \mathrm{CO}_{2}$ slightly enhanced growth, although it was not essential for growth. Colonies on MRS agar were approximately $1 \mathrm{~mm}$ in diameter, circular, entire, translucent, cream, convex and smooth. Growth appeared more dense in MRS broth, producing a thick settled layer of cells at the bottom of the tube. $\alpha$-haemolysis was observed on TSA containing sheep blood after 5-7 days incubation under anaerobic conditions. In agreement with the phylogenetically closely related species Lactobacillus casei ATCC $393^{\mathrm{T}}$, Lactobacillus paracasei ATCC $25302^{\mathrm{T}}$, and Lactobacillus rhamnosus ATCC $7469^{\mathrm{T}}$, the three novel strains grew slowly on CDC Anaerobe $5 \%$ sheep blood agar (BD) with phenylethyl alcohol (PEA) during anaerobic incubation at $36 \pm 1{ }^{\circ} \mathrm{C}$. Faint and slow growth of all the tested strains was observed in Schaedler broth (BD) during aerobic incubation at $36 \pm 1{ }^{\circ} \mathrm{C}$. Microscopically, the novel isolates appeared as chains of plump coccobacilli, with a few bacilli and cocci forms also present. Like most species of the genus Lactobacillus, the isolates did not produce catalase or oxidase, and cells were non-motile and Gram-stain-positive.

Genomic DNA was isolated from $1.0 \mathrm{ml}$ of actively growing broth culture using the DNeasy Blood \& Tissue kit (Qiagen) according to the manufacturer's protocol. PCR amplification of the entire 16S rRNA gene, the 16S$23 \mathrm{~S}$ rRNA intergenic transcribed spacer region (ITS) and the partial 23S rRNA gene as a single PCR product (hereinafter referred to as the 16S-ITS-23S) was performed using previously published primers, 16SF and 23S-R1MYC (Volokhov et al., 2007). The partial rpoB, rpoA, and $r p o C$ gene sequences of these isolates were amplified by PCR with primers rpoBF (GATGATATTGAYCACTTRGGTAACCG) and rpoBR (GCCCADACTTCCATTTCMCCRAAACG), rpoAF (TTAGTCTTCTTTACGCAATCCTAAGC) and rpoAR (ATGATCGAATTCGAAAAGCCGAAC), rpoCF (CATCCCGGTACCAGCCGGAATGATCT) and rpoCR (TGATTGATGTCAATAAGTTTGAAAGTATGCA), respectively. These primers were designed from the GenBank sequences of the corresponding genes of $L$. case $i, L$. paracase $i$ and $L$. rhamnosus, the species which were found to be closely related to the novel geese strains based on the phylogenetic analysis of their 16S rRNA genes. PCR amplification of the phenylalanyl-tRNA synthase alpha subunit gene ( $p h e S$ ) was performed using previously published primers, pheS-21F and pheS-952R (Naser et al., 2005). The determined sequences of the 16S-ITS-23S, rpoB, rpoC, rpoA and pheS genes, and deduced amino acid sequences of RpoB, RpoC, RpoA and PheS were compared to the GenBank nucleotide and protein databases using BLASTN and BLASTP algorithms, respectively. Nucleotide and amino acid sequences were aligned using CLUSTAL_X software (http://www.clustal.org). Inter- and intra-species similarity scores for each gene were generated using BioEdit software (http://www.mbio.ncsu.edu/BioEdit/bioedit.html). Phylogenetic analysis was conducted using MEGA version 4 software (Tamura et al., 2007). Phylogenetic trees were constructed and compared in MEGA 4 software using neighbour-joining, maximum-parsimony, UPGMA and minimum evolution algorithms. The robustness of the individual branches was estimated by bootstrap analysis with 1000 replicates. The analogous genetic targets of Streptococcus equinus were used as outgroup sequences during phylogenetic comparisons, and bootstrap analyses were performed using 1000 bootstrapped iterations. No differences were observed between 
the trees created with the different phylogenetic algorithms. At the time of the isolation of strain SL1 $108^{\mathrm{T}}$, its $16 \mathrm{~S}$ rRNA gene sequence showed low sequence similarity to known species of LAB; all similarities were $94-95 \%$ or less, and the closest known relatives were $L$. casei, $L$. paracasei and $L$. rhamnosus, LAB species that are widely distributed in nature (Claesson et al., 2008). However, the recently published species Lactobacillus saniviri (Oki et al., 2012) demonstrated the highest $16 \mathrm{~S}$ rRNA gene sequence similarity (97\%) to strain SL1108 ${ }^{\mathrm{T}}$. Phylogenetically, based on the $16 \mathrm{~S}$ rRNA, $r p o B$ and $r p o A$ gene sequences, strain SL $1108^{\mathrm{T}}$ was found to be a member of the L. casei group (Felis \& Dellaglio, 2007), which includes $L$. casei, $L$. paracasei, $L$. rhamnosus and $L$. saniviri (Fig. 1 and Figs S1 and S2, available in IJSEM Online). The 16S rRNA gene sequence similarities of strain SL1 $108^{\mathrm{T}}$ with $L$. casei, $L$. paracasei and $L$. rhamnosus were lower than the similarity threshold of $97 \%$ recommended for species differentiation by using genomic DNA-DNA hybridization (Stackebrandt \& Goebel, 1994). Therefore DNA-DNA hybridization between strain SL1108 ${ }^{\mathrm{T}}$ and the phylogenetically closely related LAB species was not performed, in agreement with reports for other $\mathrm{LAB}$ with similar 16S rRNA gene sequence similarity values (Cousin et al., 2012; Kawasaki et al., 2011a, b). However, because $L$. saniviri DSM $24301^{\mathrm{T}}$ was found to share $97 \% 16 \mathrm{~S} \mathrm{rRNA}$ gene sequence similarity to strain $\mathrm{SL} 1108^{\mathrm{T}}$, the comparison of several genetic regions $(r p o B, r p o C$, pheS and rpoA genes, and the 16S-ITS-23S) and EcoRI ribotyping, in addition to the biochemical tests, were performed for both species. For this purpose, in addition to the sequences available for $L$. saniviri DSM $24301^{\mathrm{T}}$ in GenBank (16S rRNA, pheS and $r p o A)$, sequencing of the 16S-ITS-23S, $r p o B$ and $r p o C$ genes for this species was performed during this study, and resulting sequences were deposited in Genbank under accession numbers JN644756, JN644760, and JN644761, respectively.

Despite the $97 \%$ 16S rRNA gene sequence similarity between strain SL1 $108^{\mathrm{T}}$ and L. saniviri DSM $24301^{\mathrm{T}}$, several species-specific regions within the 16S rRNA gene and the ITS were found for both species (Figs S3 and S4). These differences clearly demonstrate that strain $\mathrm{SL}_{1108^{\mathrm{T}}}$ and $L$. saniviri DSM $24301^{\mathrm{T}}$ are distinct species. During our search for other closely related sequences to the 16S rRNA gene of strain SL1 $108^{\mathrm{T}}$ or L. saniviri DSM $24301^{\mathrm{T}}$, we found one $16 \mathrm{~S}$ rRNA gene sequence (GenBank accession number HM534767) that was identical to the 16S rRNA gene of $L$. saniviri DSM $24301^{\mathrm{T}}$. This sequence from Lactobacillus sp. Akpobrol was isolated from the stomach of a honey bee and deposited in Genbank, and was published (Vásquez et al., 2012) while this manuscript was in press.

The similarities among the $r p o A, r p o C, r p o B$ and pheS gene sequences of strain SL1 $108^{\mathrm{T}}$ and the closest neighbouring species ranged from 75-85\% [Tables S1 (rpoA) and S2 $(r p o B)$, and data not shown]. Gene sequences from this study were deposited in GenBank under accession numbers HQ022861, HQ022858, HQ917698, JF313457, JN644756 and JN644760-JN644763.
Our attempt to amplify the $\operatorname{gyrB}$ gene of strain $\mathrm{SL} 1108^{\mathrm{T}}$ and L. saniviri DSM $24301^{\mathrm{T}}$ using primers designed from the gyrB gene sequences of $L$. casei and L. rhamnosus, gyrBF (GTGACGGACAAGAAAGAAWCGGCCGAAG) and gyrBR (CGCCGCGGYTCAACATGATCRCCCATC), failed for both species. However these primers did efficiently amplify an unknown DNA sequence (GenBank accession number JF313457) that was unique to strain SL1 $108^{\mathrm{T}}$ and found to be partially similar to orf106 gene $(70 \%)$ of $L$. casei BL23 (FM177140), phage hypothetical protein $(74 \%)$ of L. casei bacteriophage A2 (AJ251789), and phage hypothetical protein $(70 \%)$ of Macrococcus caseolyticus JCSC5402 (AP009484). Using this unique DNA sequence of strain SL1108 ${ }^{\mathrm{T}}$, species-specific primers were designed (L.brantaeF GTTGCGTCTGGTTGCGAGTTGTG and L.brantaeR TGATAGCGGGCGTGACGTTGATG) which subsequently amplified a 776 bp DNA fragment from strains SL1108 ${ }^{\mathrm{T}}$, SL1170 and SL60106, but not from the phylogenetically closely related species L. casei ATCC $393^{\mathrm{T}}$, L. paracasei ATCC $25302^{\mathrm{T}}$, L. rhamnosus ATCC $7469^{\mathrm{T}}$, and $L$. saniviri DSM $24301^{\mathrm{T}}$ (data not shown).

On the basis of phylogenetic analysis of the 16S rRNA, rpoA and $r p o B$ gene sequences as well as sequence analysis of additional genetic targets ( $r p o C$ and pheS genes, and the ITS), the novel strain SL1 $108^{\mathrm{T}}$ did not belong to any recognised species of the genus Lactobacillus. The two additional strains SL1170 and SL60106 shared the same growth characteristics as strain $\mathrm{SL} 1108^{\mathrm{T}}$, and had $99.9 \%$ nucleotide similarity in $16 \mathrm{~S}$ rRNA, rpoA, rрoB, rpoC and pheS gene sequences to strain SL1108 ${ }^{\mathrm{T}}$.

Phylogenetic relatedness of the strains SL1108 ${ }^{\mathrm{T}}$, SL1170 and SL60106 to L. casei, L. paracasei, L. rhamnosus and $L$. saniviri directed us to perform ribotyping of representative strains as an additional discriminating test. Automated ribotyping was performed on a Riboprinter system (DuPont Qualicon) using EcoRI as the restriction enzyme as described previously (Brisse et al., 2002; Massi et al., 2004; Švec et al., 2010). The ribopatterns of strains SL1 $108^{\mathrm{T}}$, SL1170 and SL60106 were very similar (Fig. 2). However they did not match $(\geqslant 0.7-0.8$ similarity index value indicates high level similarity) any pattern in the database which included more than 70 unique species of the genus Lactobacillus (data not shown). Comparison of the ribotype pattern of SL1 $108^{\mathrm{T}}$ with $L$. casei ATCC $393^{\mathrm{T}}$, L. paracasei ATCC $25302^{\mathrm{T}}$, $L$. rhamnosus ATCC $7469^{\mathrm{T}}$, L. saniviri DSM $24301^{\mathrm{T}}$ and strains of other species of the genus Lactobacillus showed distinct differences among the species (Fig. 3) with similarity indexes ranging from 0.03 to 0.51 , indicating a low degree of similarity (Brisse et al., 2002).

The biochemical characteristics of strain $\mathrm{SL} 1108^{\mathrm{T}}$ were compared to L. casei ATCC $393^{\mathrm{T}}$, L. paracasei ATCC $25302^{\mathrm{T}}$, L. rhamnosus ATCC $7469^{\mathrm{T}}$, and L. saniviri DSM $24301^{\mathrm{T}}$ (Table 1). For strain SL1108 ${ }^{\mathrm{T}}$, L. casei ATCC $393^{\mathrm{T}}$, $L$. paracasei ATCC $25302^{\mathrm{T}}$ and L. rhamnosus ATCC $7469^{\mathrm{T}}$ biochemical characteristics were determined using standard laboratory methods (conventional tube tests) and rapid 


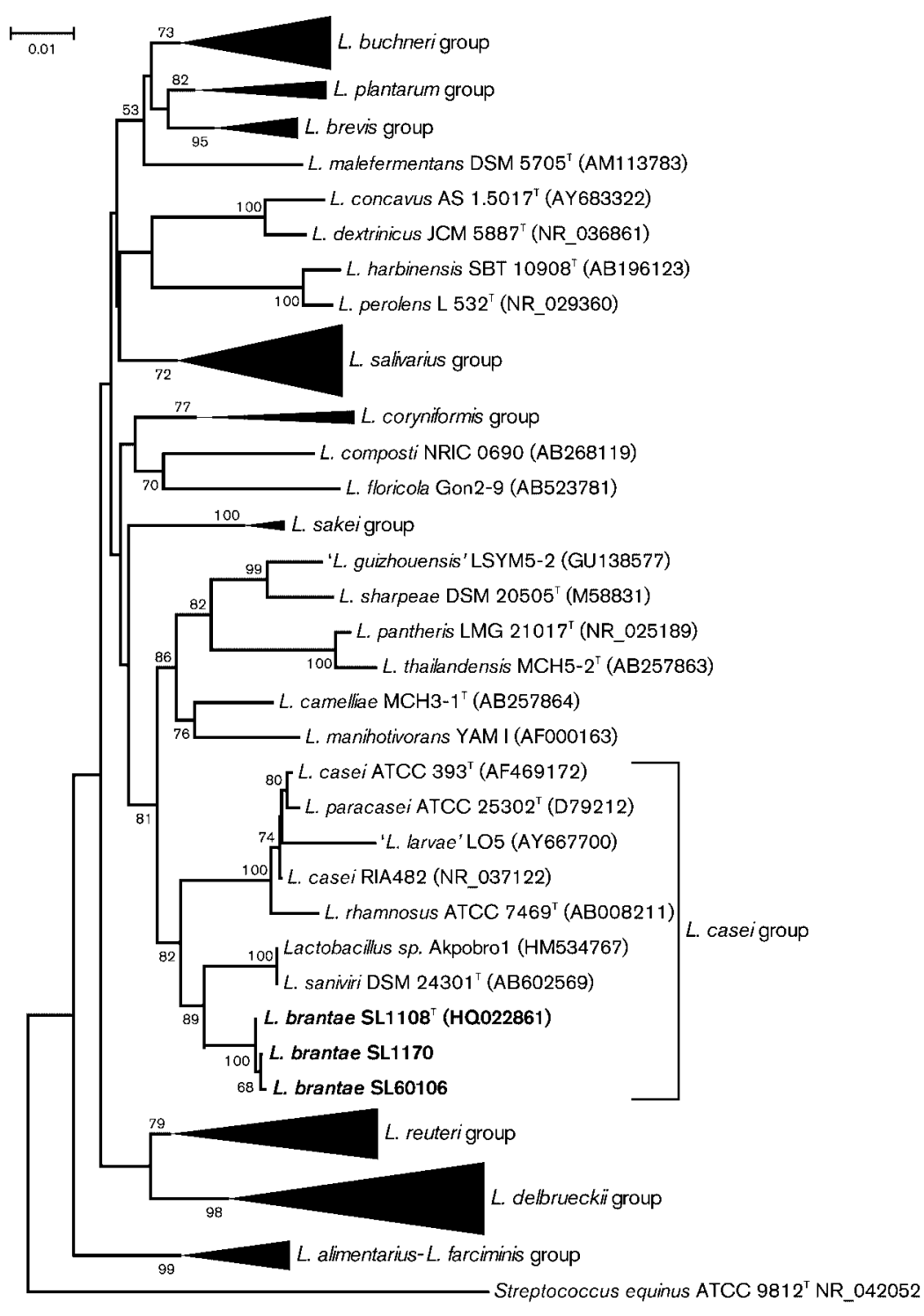

Fig. 1. Dendrogram showing phylogenetic relationships of Lactobacillus brantae sp. nov. with other lactic acid bacteria based on $16 \mathrm{~S}$ rRNA gene sequences. The trees were constructed based on the gene sequences of 151 different Lactobacilli using the minimum evolution method in the MEGA 4 software package. Bootstrap values presented at corresponding branches were evaluated from 1000 replications. GenBank accession numbers are indicated in parentheses. Major phylogenetic groups of Lactobacilli are indicated. Bar, 0.01 substitutions per nucleotide position. commercial systems, including API $50 \mathrm{CH}$ strips, Vitek Compact 2 GP and ANC cards (bioMérieux), and Gen III plates (Biolog), all commonly used for biochemical characterization of Lactobacilli (Charteris et al., 2001; Di Cagno et al., 2010; Johansson et al., 1995). All commercial biochemical tests were performed according to manufacturers' procedures. The biochemical test results for $L$. saniviri DSM $24301^{\mathrm{T}}$ were taken from a recent publication by Oki et al. (2012). In addition, several tests with $L$. saniviri DSM $24301^{\mathrm{T}}$ (arabinose, fructose, glucose, glycerol, lactose, maltose, mannitol, mannose, rhamnose, ribose, sucrose and xylose) were evaluated in this study using conventional tube tests and agreed with the previously published data of Oki et al. (2012) (Table 1). The two additional novel strains, SL1170 and SL60106, were also analysed for their biochemical characteristics using conventional tube tests and Vitek Compact 2 GP and ANC cards. The Vitek Compact 2 GP and ANC cards and the API $50 \mathrm{CH}$ strip profiles failed to produce a clear identification of these novel strains to the species level, but were useful to determine the biochemical capability of the strains. Use of the Biolog Gen III system indicated Lactobacillus sake and Lactobacillus brevis to be the closest relatives of strain SL1 $108^{\mathrm{T}}$, although the similarity scores were very low $(0.12$ and 0.07 , respectively). All four species of the genus Lactobacillus tested (L. casei ATCC $393^{\mathrm{T}}$, L. paracasei ATCC $25302^{\mathrm{T}}$, L. rhamnosus ATCC $7469^{\mathrm{T}}$ and strain SL1 $108^{\mathrm{T}}$ ) were able to utilize glucose, fructose, mannose, $\mathrm{N}$-acetyl-D-glucosamine (NAG) and butyrate, but not arabinose, fucose, glycogen, raffinose, xylose, adonitol, arabitol, dulcitol, inulin, inosine, xylitol, acetic acid, formic acid, fusidic acid, glucuronic acid, mucic acid, propionic acid or quinic acid. All four species were negative in tests for urease, indole and gelatinase; were unable to grow in increased concentrations of $\mathrm{NaCl}(6.5 \%, \mathrm{w} / \mathrm{v})$; did not utilise any of the amino acids tested (alanine, arginine, 


\begin{tabular}{|c|c|c|c|}
\hline \multirow[b]{2}{*}{ Strain } & \multirow{2}{*}{$\begin{array}{l}\text { Relative } \\
\text { SIM }\end{array}$} & \multicolumn{2}{|c|}{ RiboPrint ${ }^{\text {Tu }}$ Pattern } \\
\hline & & 1 kbp & 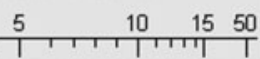 \\
\hline $\begin{array}{l}\text { SL1108 } \\
\text { SL1170 }\end{array}$ & $\begin{array}{l}1.00 \\
0.91\end{array}$ & & \\
\hline SL60106 & 0.77 & & \\
\hline
\end{tabular}

Fig. 2. EcoRl riboprint patterns for the three strains of $L$. brantae sp. nov. Similarity Index (SIM) is relative to strain SL1108'.

aspartic acid, glutamic acid, histidine, proline and serine); and were unable to grow in the presence of guanidine, lincomycin, minocycline, nalidixic acid, rifamycin, troleandomycin or vancomycin. However many of the biochemical tests did provide differential reactions for these four species (Table 1); strain SL1 $108^{\mathrm{T}}$ reacted uniquely with cellobiose, galactose, mannitol, citric acid and aesculin (all negative), and dextrin and melibiose (both positive). Strain SL1 $108^{\mathrm{T}}$ was also negative in tests for L-proline arylamidase, Lpyrrolydonyl-arylamidase, and in the Voges-Proskauer test. Furthermore, comparison of data for strain SL1 $108^{\mathrm{T}}$ and $L$. saniviri DSM $24301^{\mathrm{T}}$ demonstrated that the biochemical tests for cellobiose, aesculin, galactose, gentiobiose, mannitol, melezitose, ribose, salicin, sucrose, trehalose, raffinose, turanose, amygdalin and arbutin could be used for differentiation between L. saniviri DSM $24301^{\mathrm{T}}$ and the novel strains, SL1108 ${ }^{\mathrm{T}}$, SL1170 and SL60106.

Although SL1108 ${ }^{\mathrm{T}}$, SL1170 and SL60106 demonstrated complete concordance with their biochemical profiles obtained with the Vitek Compact 2 GP and ANC cards, there were conflicting results for strain $\mathrm{SL} 1108^{\mathrm{T}}, L$. paracasei ATCC $25302^{\mathrm{T}}$ and L. rhamnosus ATCC $7469^{\mathrm{T}}$ in a few tests (D-galactose, lactose, maltose, salicin and sorbitol) obtained with these cards compared to the Biolog
Gen III system. All discrepant tests were investigated using the sugars in conventional test tubes and were determined to match the results from the Biolog Gen III system (data not shown).

Peptidoglycan type analysis was performed for strain SL1 108 ${ }^{\mathrm{T}}$, L. casei ATCC $393^{\mathrm{T}}$, L. paracasei ATCC $25302^{\mathrm{T}}$ and L. rhamnosus ATCC $7469^{\mathrm{T}}$. The strains were grown in MRS broth (Sigma-Aldrich Inc.) and harvested at the time when the $\mathrm{OD}_{600}$ of the cultures were 1.0 as measured by using an UltroSpec 3100 pro spectrophotometer (Amersham Biosciences). Peptidoglycan from the harvested cells was purified as described by McPherson \& Popham (2003) and amino acid analysis was performed as described by GonzálezCastro et al. (1997). Strain SL1108 ${ }^{\mathrm{T}}$ had the peptidoglycan type L-Lys-D-Asp, which was identical to the previously published peptidoglycan type for $L$. casei, $L$. paracasei and L. rhamnosus (Felis \& Dellaglio, 2007), and confirmed in this study. It was also identical to the peptidoglycan type for the recently published $L$. saniviri (Oki et al., 2012). In all the tested strains there was no diaminopimelic acid detected in the peptidoglycan, and the peptidoglycan side chains appeared to be Ala-Glu-Lys-Ala (with approximate ratios 2 Ala: 1 Glu: 1 Asp : 1 Lys) with Asp crossbridges in the crosslinks, in agreement with that previously described for $L$. casei (Billot-Klein et al., 1997). Thus, the primary structure of the peptidoglycan of all the tested species belonged to subgroup A4 (Billot-Klein et al., 1997; Schleifer \& Kandler, 1972).

Fatty acid profile analysis was performed for strain SL1 $108^{\mathrm{T}}$, L. casei ATCC $393^{\mathrm{T}}$, L. paracasei ATCC $25302^{\mathrm{T}}$ and $L$. rhamnosus ATCC $7469^{\mathrm{T}}$. The strains were grown in MRS broth at $37.0 \pm 1.0{ }^{\circ} \mathrm{C}$ for $48 \mathrm{~h}$. For gas chromatography with flame-ionization detection (GC-FID) analysis, bacterial cells were harvested and whole-cell fatty acid methyl esters (FAMEs) from triplicate samples were prepared by saponification, methylation and extraction into hexane/methyl tert-butyl ether, as previously described

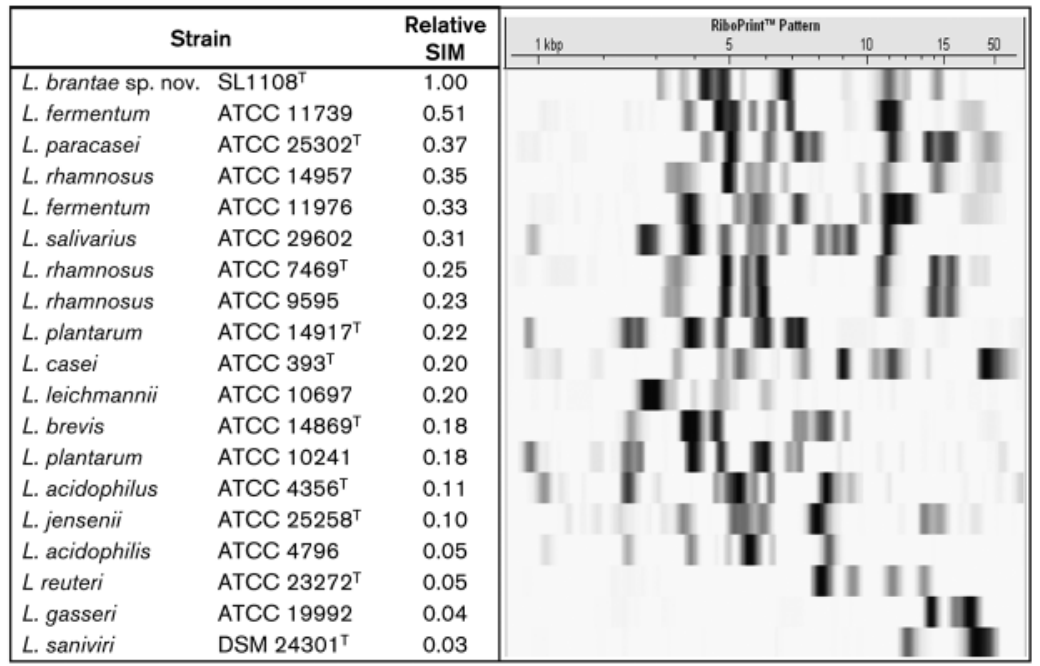

Fig. 3. EcoRI riboprint patterns for various species of the genus Lactobacillus in compar-

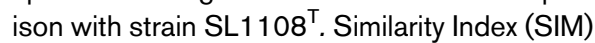
is relative to strain $S_{11108^{\top}}$. 
Table 1. Biochemical characteristics of strain $S L 1108^{\top}$ and phylogenetically closely related species of the genus Lactobacillus

Strains: 1, SL1 $108^{\mathrm{T}}$; 2, L. casei ATCC $393^{\mathrm{T}}$; 3, L. paracasei ATCC $25302^{\mathrm{T}} ; 4$, L. rhamnosus ATCC $7469^{\mathrm{T}}$; 5 , L. saniviri DSM $24301^{\mathrm{T}}$. Data are from this study except for L. saniviri DSM $24301^{\mathrm{T}}$ which is taken from Oki et al., 2012. +, Positive; -, negative; ND, no data available.

\begin{tabular}{|c|c|c|c|c|c|}
\hline Tests $^{*}$ & 1 & 2 & 3 & 4 & 5 \\
\hline Amylose $^{c}$ & - & + & - & + & $\mathrm{ND}$ \\
\hline Citric $\operatorname{acid}^{c}$ & - & + & + & + & $\mathrm{ND}$ \\
\hline Dextrin $^{c}$ & + & - & - & - & $\mathrm{ND}$ \\
\hline Galactose $^{c}$ & - & + & + & + & + \\
\hline D-Galactose $\mathrm{e}^{b}$ & - & + & + & + & + \\
\hline Gentiobiose $^{c}$ & - & + & - & + & + \\
\hline Gluconic acid ${ }^{c}$ & + & + & + & - & $\mathrm{ND}$ \\
\hline Glycerol $^{c}$ & + & + & - & + & + \\
\hline Inositol $^{c}$ & - & - & - & + & - \\
\hline $1 \%$ Sodium lactate ${ }^{c}$ & - & - & + & - & ND \\
\hline Maltose $^{b}$ & - & - & + & - & + \\
\hline Mannitol $^{c}$ & - & + & + & + & + \\
\hline D-Mannitol $^{d}$ & - & + & + & + & + \\
\hline Melezitose $^{a}$ & - & + & - & + & + \\
\hline Melibiose $^{c}$ & + & - & - & - & + \\
\hline Pectin $^{c}$ & + & - & - & + & $\mathrm{ND}$ \\
\hline Pyruvate $^{c}$ & - & - & + & + & $\mathrm{ND}$ \\
\hline Rhamnose $^{c}$ & - & - & - & + & - \\
\hline Ribose $^{c}$ & - & - & + & + & + \\
\hline D-Ribose $e^{b}$ & - & - & + & + & + \\
\hline Salicin $^{c}$ & - & + & + & + & + \\
\hline Turanose $^{c}$ & + & - & - & + & - \\
\hline Tween $40^{c}$ & + & - & - & - & $\mathrm{ND}$ \\
\hline Voges-Proskauer $^{a}$ & - & + & + & + & ND \\
\hline D-Amygdalin ${ }^{d}$ & - & + & - & + & + \\
\hline$\beta$-Galactosidase ${ }^{d}$ & - & + & - & - & $\mathrm{ND}$ \\
\hline Ala-Phe-Pro arylamidase ${ }^{d}$ & + & - & + & - & $\mathrm{ND}$ \\
\hline Ala-Phe-Pro arylamidase ${ }^{b}$ & + & - & - & - & $\mathrm{ND}$ \\
\hline$\beta$-Galactopyranosidase ${ }^{d}$ & - & + & - & - & $\mathrm{ND}$ \\
\hline L-Proline arylamidase ${ }^{d}$ & - & + & + & + & $\mathrm{ND}$ \\
\hline L-Pyrrolydonyl-arylamidase ${ }^{d}$ & - & + & + & + & $\mathrm{ND}$ \\
\hline Methyl- $\beta$-D-glucopyranoside ${ }^{d}$ & - & + & - & + & ND \\
\hline Arbutin $^{b}$ & - & + & - & + & + \\
\hline 5-Bromo-4-chloro-3-indoxyl- $\beta$-glucoside ${ }^{b}$ & - & + & - & + & $\mathrm{ND}$ \\
\hline$\alpha$-Arabinosidase ${ }^{b}$ & - & + & - & - & $\mathrm{ND}$ \\
\hline Growth on CDC Anaerobe $5 \%$ SBA with $\mathrm{PEA}^{e}$ & Slow & Slow & Slow & Slow & $\mathrm{ND}$ \\
\hline Growth in Schaedler broth ${ }^{e}$ & Slow & Slow & Slow & Slow & $\mathrm{ND}$ \\
\hline
\end{tabular}

${ }^{*}$ Results for columns 1-4 obtained with: $a$, API 50CH strips; $b$, VITEK 2 ANC card; $c$, Biolog Gen III plates; $d$, VITEK 2 GP card; $e$, conventional tube. 
(Whittaker et al., 2007). The GC was an Agilent 6890 with a flame-ionization detector and an auto sampler and injector (7683; Agilent). A $25 \mathrm{~cm}$ (length) x $0.2 \mathrm{~mm}$ ID x $0.33 \mu \mathrm{m}$ film thickness, cross-linked $5 \%$ phenylmethyl silicone fused silica capillary column (19091B-102; Agilent) was used to separate the fatty acids. The FAMEs were analysed by GC using the rapid Microbial Identification System (MIS, MIDI Inc.) software (RTSB50) to identify the relative amounts of fatty acids in the bacteria (Sasser, 1990). Results were expressed as percentage of total fatty acids (Table 2). The major fatty acids of the four species of the genus Lactobacillus were $\mathrm{C}_{14: 0}, \mathrm{C}_{16: 0}, \mathrm{C}_{18: 1} \omega 9 c, \mathrm{C}_{18: 1} \omega 7 c$, and summed feature $\mathrm{C}_{16: 1} \omega 7 c / \mathrm{C}_{16: 1} \omega 6 c$. The percentages of all the major fatty acids were significantly different for strain SL1108 ${ }^{\mathrm{T}}$ compared to the other three species (Table 2). Therefore FAME analysis can be used to differentiate strain SL1 $108^{\mathrm{T}}$ from the phylogenetically closely related species of the genus Lactobacillus.

The isomers of lactic acid formed from glucose during the growth of strain SL1108 ${ }^{\mathrm{T}}$ in MRS broth were determined with the TC D-/L-Lactic Acid test kit (Boehringer Mannheim), and strain $\mathrm{SL} 1108^{\mathrm{T}}$ was found to produce L-lactic acid isomer (data not shown).

Assessment and prediction of genomic $\mathrm{G}+\mathrm{C}$ content for strain $\mathrm{SL} 1108^{\mathrm{T}}$ in comparison with $L$. casei ATCC 334, $L$. rhamnosus GG, L. saniviri DSM $24301^{\mathrm{T}}$ and Lactobacillus delbrueckii subsp. bulgaricus ATCC 11842 was performed by the analysis of $\mathrm{G}+\mathrm{C}$ content for the 16S-ITS-23S, $r p o B$, rpoC, pheS and rpoA gene sequences (Table S3). This approach of assessing and predicting genomic $\mathrm{G}+\mathrm{C}$ content based on the comparison of $\mathrm{G}+\mathrm{C}$ content of individual housekeeping genes compared to the results of DNA G $+C$ content determined experimentally by the HPLC (high performance liquid chromatography) technique, has been successfully demonstrated and published for multiple bacterial species (Fournier et al., 2006; Kuhnert \& Korczak, 2006; Lorén et al., 2010; Zavala et al., 2005). Previously published data demonstrated minimal differences $( \pm 3-5 \%)$ between genomic $\mathrm{G}+\mathrm{C}$ content predicted from analysis of individual housekeeping genes and the results of $\mathrm{G}+\mathrm{C}$ content estimated using HPLC. The predicted genomic $\mathrm{G}+\mathrm{C}$ contents based on the analysis of individual housekeeping genes for $L$. casei ATCC 334, L. rhamnosus GG, L. saniviri DSM $24301^{\mathrm{T}}$ and L. delbrueckii subsp. bulgaricus ATCC 11842 (Table S3) were very similar to previously published data (Felis \& Dellaglio, 2007; Oki et al., 2012) for these four reference species, and/or the data available in GenBank from their whole genome sequencing projects (Genbank accession number CP000423, FM179322, and CR954253 for L. casei, $L$. rhamnosus, and L. delbrueckii subsp. bulgaricus, respectively). The predicted genomic G+C content for strain SL1108 ${ }^{\mathrm{T}}$ was $48.2 \pm 2.6 \mathrm{~mol} \%$.

On the basis of phenotypic, chemotaxonomic characteristics and phylogenetic data, the three isolates, $\mathrm{SL} 1108^{\mathrm{T}}$, SL1170 and SL60106, represent a novel species of the genus Lactobacillus, for which the name Lactobacillus brantae sp. nov. is proposed.

\section{Description of Lactobacillus brantae sp. nov.}

Lactobacillus brantae (bran'ta.e. L. gen. n. brantae of Branta, isolated from Branta canadensis).

Cells are Gram-stain-positive, catalase-negative, non-sporeforming, non-motile rods, approximately $0.5 \times 4.0 \mu \mathrm{m}$, appearing as chains of plump coccobacilli, with a few bacilli and cocci forms also present. Colonies are formed on MRS agar, Rogosa SL agar and sheep blood agar under aerobic and anaerobic conditions. When incubated at $37^{\circ} \mathrm{C}$, good

Table 2. Cellular fatty acid compositions of strain $S L 1108^{\top}$ and phylogenetically closely related species of the genus Lactobacillus

Strains: 1 , SL $1108^{\mathrm{T}} ; 2$, L. casei ATCC $393^{\mathrm{T}}$; 3, L. rhamnosus ATCC $7469^{\mathrm{T}} ; 4$, L. paracasei ATCC $25302^{\mathrm{T}}$. All data are from this study. Values are percentages of total fatty acids and are the mean of triplicate analysis \pm standard deviation. Means for a variable not sharing a common superscript letter are significantly different $(P<0.05)$ as determined by the Duncan multiple comparison method, which was applied only if significant differences were determined to exist by ANOVA.

\begin{tabular}{|lccccc|}
\hline Cellular fatty acid & $\mathbf{1}$ & $\mathbf{2}$ & $\mathbf{3}$ & $\mathbf{4}$ & $\boldsymbol{P}$-value \\
\hline $\mathrm{C}_{14: 0}$ & $9.72 \pm 0.30^{c}$ & $14.01 \pm 0.81^{d}$ & $3.78 \pm 0.30^{a}$ & $8.19 \pm 0.44^{b}$ & $<0.001$ \\
$\mathrm{C}_{15: 0}$ & $1.01 \pm 0.02^{c}$ & $0.69 \pm 0.06^{b}$ & $0.00 \pm 0.00^{a}$ & $0.70 \pm 0.09^{b}$ & $<0.001$ \\
$\mathrm{C}_{16: 1} \omega 5 c$ & $1.32 \pm 0.03^{b}$ & $1.48 \pm 0.06^{c}$ & $0.38 \pm 0.05^{a}$ & $1.77 \pm 0.08^{d}$ & $<0.001$ \\
$\mathrm{C}_{16: 0}$ & $27.57 \pm 0.64^{a}$ & $42.88 \pm 1.44^{c}$ & $37.23 \pm 1.23^{b}$ & $41.06 \pm 0.59^{c}$ & $<0.001$ \\
$\mathrm{C}_{17: 0}$ ante & $2.18 \pm 0.08^{c}$ & $1.13 \pm 0.33^{b}$ & $0.08 \pm 0.13^{a}$ & $1.26 \pm 0.03^{b}$ & $<0.001$ \\
$\mathrm{C}_{17: 1} \omega 8 c$ & $2.10 \pm 0.03^{d}$ & $0.35 \pm 0.30^{b}$ & $0.00 \pm 0.00^{a}$ & $0.90 \pm 0.03^{c}$ & $<0.001$ \\
$\mathrm{C}_{18: 1} \omega 9 c$ & $26.27 \pm 1.63^{d}$ & $11.95 \pm 0.25^{b}$ & $3.99 \pm 0.13^{a}$ & $20.21 \pm 0.43^{c}$ & $<0.001$ \\
$\mathrm{C}_{18: 1} \omega 7 c$ & $6.46 \pm 0.35^{a}$ & $14.01 \pm 0.29^{c}$ & $17.93 \pm 1.13^{d}$ & $12.40 \pm 0.10^{b}$ & $<0.001$ \\
$\mathrm{C}_{18: 0}$ & $0.73 \pm 1.26^{a}$ & $1.21 \pm 1.06^{a}$ & $3.71 \pm 0.82^{b}$ & $2.19 \pm 0.20^{a}, b$ & 0.019 \\
$\mathrm{C}_{19: 0}$ cyclo $\omega 8 c$ & $0.00 \pm 0.00^{a}$ & $0.00 \pm 0.00^{a}$ & $23.33 \pm 1.31^{b}$ & $0.00 \pm 0.00^{a}$ & $<0.001$ \\
$\mathrm{C}_{20: 0}$ & $2.60 \pm 0.76^{d}$ & $0.13 \pm 0.11^{a}$ & $1.59 \pm 0.12^{c}$ & $0.83 \pm 0.42^{b}$ & 0.001 \\
Summed feature $\mathrm{C}_{16: 1} \omega 7 \mathrm{cl}$ & $14.44 \pm 0.22^{d}$ & $8.98 \pm 0.44^{c}$ & $5.48 \pm 0.78^{a}$ & $7.79 \pm 0.25^{b}$ & $<0.001$ \\
$\mathrm{C}_{16: 1} \omega 6 c$ & & & & & \\
\hline
\end{tabular}


growth appears in $48 \mathrm{~h}$. Growth occurs at $25-40{ }^{\circ} \mathrm{C}$, but not at $45{ }^{\circ} \mathrm{C}$. At $37{ }^{\circ} \mathrm{C}$, growth occurs in the presence of 2.0 $4.0 \%(\mathrm{w} / \mathrm{v}) \mathrm{NaCl}$ but not in the presence of $6.5 \%(\mathrm{w} / \mathrm{v})$ $\mathrm{NaCl}$. Colonies grow slowly on CDC Anaerobe 5\% sheep blood agar with phenylethyl alcohol during anaerobic incubation. Colonies on MRS plates are $1 \mathrm{~mm}$ in diameter, circular, entire, translucent, cream, convex and smooth. Growth appeared more dense in MRS broth, producing a thick settled layer of cells at the bottom of the tube. Cells are facultatively heterofermentative and do not produce gas from glucose. Negative result in tests for urease, indole and gelatinase. The type strain SL1108 ${ }^{\mathrm{T}}$ utilizes glucose, fructose, mannose, NAG and butyrate, but not arabinose, fucose, glycogen, raffinose, xylose, adonitol, arabitol, dulcitol, inulin, inosine, xylitol, acetic acid, formic acid, fusidic acid, glucuronic acid, mucic acid, propionic acid or quinic acid. The type strain $\mathrm{SL} 1108^{\mathrm{T}}$ did not use alanine, arginine, aspartic acid, glutamic acid, histidine, proline or serine, and did not grow in the presence of guanidine, lincomycin, minocycline, nalidixic acid, rifamycin, troleandomycin or vancomycin. In comparison to the phylogenetically closely related species $L$. casei ATCC $393^{\mathrm{T}}$, L. paracasei ATCC $25302^{\mathrm{T}}$, L. rhamnosus ATCC $7469^{\mathrm{T}}$ and L. saniviri DSM $24301^{\mathrm{T}}$, strain $\mathrm{SL} 1108^{\mathrm{T}}$ reacted uniquely with cellobiose, galactose, mannitol, citric acid and aesculin (all negative), and dextrin (positive), and was negative in tests for L-proline arylamidase, L-pyrrolydonyl-arylamidase, and in the VogesProskauer test. Biochemical tests for cellobiose, aesculin, galactose, gentiobiose, mannitol, melezitose, ribose, salicin, sucrose, trehalose, raffinose, turanose, amygdalin and arbutin can be used for differentiation between Lactobacillus saniviri and the novel strains. The type strain $\mathrm{SL} 1108^{\mathrm{T}}$ has peptidoglycan type L-Lys-D-Asp, and major fatty acids are $\mathrm{C}_{14: 0}$, $\mathrm{C}_{16: 0}, \mathrm{C}_{18: 1} \omega 9 c, \mathrm{C}_{18: 1} \omega 7 c$ and summed feature $\mathrm{C}_{16: 1} \omega 7 c l$ $\mathrm{C}_{16: 1} \omega 6 c$.

The type strain is SL1108 ${ }^{\mathrm{T}}\left(=\right.$ ATCC BAA $-2142^{\mathrm{T}}=\mathrm{LMG}$ $26001^{\mathrm{T}}=$ DSM $23927^{\mathrm{T}}$ ) and was isolated from the faeces of apparently healthy wild Canada geese (Branta canadensis) collected in Great Falls Park, Maryland, USA in June 2010. Two additional strains are SL1170 and SL60106.

\section{Acknowledgements}

We thank Dr Maureen K. Davidson for her suggestions and critical review of this manuscript.

\section{References}

Angelakis, E. \& Raoult, D. (2010). The increase of Lactobacillus species in the gut flora of newborn broiler chicks and ducks is associated with weight gain. PLoS ONE 5, e10463.

Billot-Klein, D., Legrand, R., Schoot, B., van Heijenoort, J. \& Gutmann, L. (1997). Peptidoglycan structure of Lactobacillus casei, a species highly resistant to glycopeptide antibiotics. J Bacteriol 179, 6208-6212.

Brisse, S., Fussing, V., Ridwan, B., Verhoef, J. \& Willems, R. J. (2002). Automated ribotyping of vancomycin-resistant Enterococcus faecium isolates. J Clin Microbiol 40, 1977-1984.
Charteris, W. P., Kelly, P. M., Morelli, L. \& Collins, J. K. (2001). Quality control Lactobacillus strains for use with the API 50CH and API ZYM systems at $37{ }^{\circ} \mathrm{C}$. J Basic Microbiol 41, 241-251.

Claesson, M. J., van Sinderen, D. \& O’Toole, P. W. (2007). The genus Lactobacillus-a genomic basis for understanding its diversity. FEMS Microbiol Lett 269, 22-28.

Claesson, M. J., van Sinderen, D. \& O'Toole, P. W. (2008). Lactobacillus phylogenomics-towards a reclassification of the genus. Int J Syst Evol Microbiol 58, 2945-2954.

Cousin, S., Gulat-Okalla, M. L., Motreff, L., Gouyette, C., Bouchier, C., Clermont, D. \& Bizet, C. (2012). Lactobacillus gigeriorum sp. nov., isolated from chicken crop. Int J Syst Evol Microbiol 62, 330-334.

Damaré, J. M., Hussong, D., Weiner, R. M. \& Colwell, R. R. (1979). Aerobic and facultatively anaerobic bacteria associated with the gut of Canada geese (Branta canadensis) and whistling swans (Cygnus columbianus columbianus). Appl Environ Microbiol 38, 258-266.

Di Cagno, R., Minervini, G., Sgarbi, E., Lazzi, C., Bernini, V., Neviani, E. \& Gobbetti, M. (2010). Comparison of phenotypic (Biolog System) and genotypic (random amplified polymorphic DNA-polymerase chain reaction, RAPD-PCR, and amplified fragment length polymorphism, AFLP) methods for typing Lactobacillus plantarum isolates from raw vegetables and fruits. Int J Food Microbiol 143, 246-253.

Ehrmann, M. A., Kurzak, P., Bauer, J. \& Vogel, R. F. (2002). Characterization of lactobacilli towards their use as probiotic adjuncts in poultry. J Appl Microbiol 92, 966-975.

Endo, A., Futagawa-Endo, Y. \& Dicks, L. M. (2010). Diversity of Lactobacillus and Bifidobacterium in feces of herbivores, omnivores and carnivores. Anaerobe 16, 590-596.

Felis, G. E. \& Dellaglio, F. (2007). Taxonomy of Lactobacilli and Bifidobacteria. Curr Issues Intest Microbiol 8, 44-61.

Fournier, P. E., Suhre, K., Fournous, G. \& Raoult, D. (2006). Estimation of prokaryote genomic DNA G $+C$ content by sequencing universally conserved genes. Int J Syst Evol Microbiol 56, 1025-1029.

González-Castro, M. J., López-Hernández, J., Simal-Lozano, J. \& Oruña-Concha, M. J. (1997). Determination of amino acids in green beans by derivatization with phenylisothiocianate and high-performance liquid chromatography with ultraviolet detection. J Chromatogr Sci 35, 181-185.

Johansson, M. L., Sanni, A., Lönner, C. \& Molin, G. (1995). Phenotypically based taxonomy using API 50CH of lactobacilli from Nigerian ogi, and the occurrence of starch fermenting strains. Int $J$ Food Microbiol 25, 159-168.

Kawasaki, S., Kurosawa, K., Miyazaki, M., Sakamoto, M., Ohkuma, M. \& Niimura, Y. (2011a). Lactobacillus ozensis sp. nov., isolated from mountain flowers.. Int J Syst Evol Microbiol 61, 2435-2438.

Kawasaki, S., Kurosawa, K., Miyazaki, M., Yagi, C., Kitajima, Y., Tanaka, S., Irisawa, T., Okada, S., Sakamoto, M. \& other authors (2011b). Lactobacillus floricola sp. nov., lactic acid bacteria isolated from mountain flowers. Int J Syst Evol Microbiol 61, 1356-1359.

Kovalenko, N. K., Golovach, T. N. \& Kvasnikov, E. I. (1989). [Lactic bacteria in the digestive tract of poultry]. Mikrobiologiia 58, 137-143.

Kuhnert, P. \& Korczak, B. M. (2006). Prediction of whole-genome DNA-DNA similarity, determination of $\mathrm{G}+\mathrm{C}$ content and phylogenetic analysis within the family Pasteurellaceae by multilocus sequence analysis (MLSA). Microbiology 152, 2537-2548.

Kurzak, P., Ehrmann, M. A. \& Vogel, R. F. (1998). Diversity of lactic acid bacteria associated with ducks. Syst Appl Microbiol 21, 588-592.

London, J. (1976). The ecology and taxonomic status of the lactobacilli. Annu Rev Microbiol 30, 279-301.

Lorén, J. G., Farfán, M., Miñana-Galbis, D. \& Fusté, M. C. (2010). Prediction of whole-genome DNA G $+\mathrm{C}$ content within the genus 
Aeromonas based on housekeeping gene sequences. Syst Appl Microbiol 33, 237-242.

Massi, M., Vitali, B., Federici, F., Matteuzzi, D. \& Brigidi, P. (2004). Identification method based on PCR combined with automated ribotyping for tracking probiotic Lactobacillus strains colonizing the human gut and vagina. J Appl Microbiol 96, 777-786.

McPherson, D. C. \& Popham, D. L. (2003). Peptidoglycan synthesis in the absence of class A penicillin-binding proteins in Bacillus subtilis. J Bacteriol 185, 1423-1431.

Mundt, J. O. \& Hammer, J. L. (1968). Lactobacilli on plants. Appl Microbiol 16, 1326-1330.

Naser, S. M., Thompson, F. L., Hoste, B., Gevers, D., Dawyndt, P., Vancanneyt, M. \& Swings, J. (2005). Application of multilocus sequence analysis (MLSA) for rapid identification of Enterococcus species based on rpoA and pheS genes. Microbiology 151, 2141-2150.

Ohashi, Y. \& Ushida, K. (2009). Health-beneficial effects of probiotics: Its mode of action. Anim Sci J 80, 361-371.

Oki, K., Kudo, Y. \& Watanabe, K. (2012). Lactobacillus saniviri sp. nov. and Lactobacillus senioris sp. nov., isolated from human faeces. Int $J$ Syst Evol Microbiol 62, 601-607.

Patterson, J. A. \& Burkholder, K. M. (2003). Application of prebiotics and probiotics in poultry production. Poult Sci 82, 627-631.

Pérez Pulido, R., Ben Omar, N., Abriouel, H., Lucas López, R., Martínez Cañamero, M. \& Gálvez, A. (2005). Microbiological study of lactic acid fermentation of Caper berries by molecular and culturedependent methods. Appl Environ Microbiol 71, 7872-7879.

Sasser, M. (1990). Identification of bacteria by gas chromatography of cellular fatty acids, MIDI Technical Note 101. Newark, DE: MIDI Inc.
Schleifer, K. H. \& Kandler, O. (1972). Peptidoglycan types of bacterial cell walls and their taxonomic implications. Bacteriol Rev 36, 407-477.

Stackebrandt, E. \& Goebel, B. M. (1994). Taxonomic note: a place for DNA-DNA reassociation and 16S rRNA sequence analysis in the present species definition in bacteriology. Int J Syst Bacteriol 44, 846849.

Švec, P., Kukletová, M. \& Sedlácek, I. (2010). Comparative evaluation of automated ribotyping and RAPD-PCR for typing of Lactobacillus spp. occurring in dental caries. Antonie van Leeuwenhoek 98, 85-92.

Tamura, K., Dudley, J., Nei, M. \& Kumar, S. (2007). MEGA4: molecular evolutionary genetics analysis (MEGA) software version 4.0. Mol Biol Evol 24, 1596-1599.

Vásquez, A., Forsgren, E., Fries, I., Paxton, R. J., Flaberg, E., Szekely, L. \& Olofsson, T. C. (2012). Symbionts as major modulators of insect health: lactic acid bacteria and honeybees. PLoS ONE 7, e33188.

Volokhov, D. V., Neverov, A. A., George, J., Kong, H., Liu, S. X., Anderson, C., Davidson, M. K. \& Chizhikov, V. (2007). Genetic analysis of housekeeping genes of members of the genus Acholeplasma: phylogeny and complementary molecular markers to the 16S rRNA gene. Mol Phylogenet Evol 44, 699-710.

Whittaker, P., Keys, C. E., Brown, E. W. \& Fry, F. S. (2007). Differentiation of Enterobacter sakazakii from closely related Enterobacter and Citrobacter species using fatty acid profiles. J Agric Food Chem 55, 4617-4623.

Zavala, A., Naya, H., Romero, H., Sabbia, V., Piovani, R. \& Musto, H. (2005). Genomic GC content prediction in prokaryotes from a sample of genes. Gene 357, 137-143. 